\title{
APLCACĞ̃O DE PESQUISA NO ENSINO DE PROJETO DE ARQUITETURA: REFORMA DA PENTEENCÍ́RIA BALDOMERO CAVALCANTE PARA REGIME SEMIABERTO
}

\section{LIMA, CAMILA COSTA DE}

Arquiteta e Urbanista, UFAL, camilacostaa.26@gmail.com

\section{LIMA, SUZANN FLÁVIA CORDEIRODE}

\author{
Docente, UFAL, suzann.cordeiro@fau.ufal.br
}

\begin{abstract}
RESUMO
O estudo apresentado é resultado da disciplina 'Projetos Especiais' da Faculdade de Arquitetura e Urbanismo da Universidade Federal de Alagoas (UFAL) e vinculada à pesquisa de iniciação científica intitulada 'Estudo das tipologias arquitetônicas de unidades penais de regime fechado' (PIBIC/CNPQ/FAPEAL/UFAL). A pesquisa PIBIC contribuiu para a melhor compreensão das problemáticas projetuais da tipologia encontrada na atual Penitenciária Baldomero Cavalcante, Alagoas. Também realizando uma atividade extensionista, a disciplina propôs o desenvolvimento de projeto de Reforma da Penitenciária supracitada, classificada como de 'regime fechado de segurança máxima', objetivando uma releitura do espaço construído existente e sua adequação ao 'regime semiaberto', a partir das solicitações e sugestões da equipe de arquitetos e engenheiros, agentes penitenciários e diretores da unidade penal, procurando amenizar os conflitos inerentes ao sistema penal pela aplicação dos resultados parciais da pesquisa. O conteúdo deste artigo é de caráter descritivo/explicativo, e apresenta essa proposta arquitetônica. Metodologicamente, além da revisão bibliográfica e da análise do projeto arquitetônico foram realizadas visitas a campo, com entrevistas semi-estruturadas sobre a racionalização de fluxos, localização de ambientes e atividades, de maneira a viabilizar o uso dos componentes arquitetônicos como elementos preventivos de violência. O resultado final deste artigo é uma discussão técnica-conceitual que pretende contribuir para o conhecimento e reflexão sobre a arquitetura prisional, assim como para a prática projetual respaldada por conteúdos mais aprofundados de pesquisa. Ademais, esse tipo de trabalho se mostra essencial, pois este é um espaço pautado na visão disciplinar, o que configura um dos principais problemas para o avanço de tecnologias e propostas espaciais, incluindo a necessidade de maiores investimentos para o aprimoramento de questões técnicas, conforme exigido pela Resolução 9/2011 (CNPCP/MJ).
\end{abstract}

PALAVRAS-CHAVE: arquitetura penal; arquitetura humanizada; segurança.

\begin{abstract}
The presented study is a result of Special Projects discipline, Faculty of Architecture and Urbanism of the Alagoas Federal University (UFAL), and linked to scientific initiation research entitled 'Study of the architectural typologies of criminal units of closed regime' (PIBIC / CNPQ / FAPEAL / UFAL). The research contributed to a better knowledge about typology design problems found on the Baldomero Cavalcante Penitentiary Building, Alagoas - Brazil. Developing a practice activity, the proposed content consist in development of a Reform architectural Project of this Penitentiary building. It was classified as a Maximum Security Closed Regime Prison, aiming a re-reading of the existing built space, adapting it to the semi-open regime, based on requests and suggestions from the architects and engineers team and penitentiary agents and directors of the prison unit, seeking to minimize conflicts inherent to the prison system by applying partial results of the research. The content of this article is descriptive / explanatory, and it presents the architectural proposal. Methodically, in addition to the bibliographical review and analysis of the architectural project, visits were made to the field, with semi-structured interviews, on the rationalization of flows, location of environments and activities, so as to make feasible the use of architectural components as preventive elements of violence. The final result of this article is a technical-conceptual discussion that intends to contribute to the knowledge and reflection on prison architecture, as well as to the project practice backed by more in-depth research contents. In addition, this type of research is essential because a space based on the disciplinary view, which is one of the main problems for the advancement of technologies and space proposals, includes the need for greater investments to improve technical issues, as required by Resolution 9/2011 (CNPCP / MJ).
\end{abstract}

KEY-WORDS: architecture criminal; architecture humanized; security.

\section{INTRODUÇÃO}

No espaço penal, mais do que em qualquer outro exemplar de espaço projetado, a imposição da ordem se instala na tentativa de limitar as ações que ali se desenrolarão, desindividualizar o sujeito (FOUCAULT, 2003), hierarquizar poderes (controlados e controladores), serializar e segregar pessoas, como que a construir relicários "da escória" social (CORDEIRO, 2010). 
O Brasil possui uma das mais avançadas leis penitenciárias da América Latina, Lei n 7.210, a Lei de Execuções Penais, de 11 de julho de 1984, que assegura todos os direitos fundamentais, preconizados na Constituição Federal, não atingidos pela pena, perpassados por aspectos recuperadores de tratamento aos condenados. Em complemento, a Resolução de 11 de novembro de 1994, do Conselho Nacional de Política Criminal e Penitenciária (CNPCP) fixa regras mínimas de tratamento do preso no Brasil, assegurando ao interno todos os direitos que a sentença não atingiu e a Resolução nº 09 de 18 de novembro de 2011 estabelece as Diretrizes Básicas para a Arquitetura Penal atualizando as antigas Diretrizes, de acordo com os pressupostos do CNPCP. Apesar disso, o espaço penitenciário brasileiro ainda reproduz as masmorras medievais, cujo objetivo é manter segregados, "transformando, cada vez mais, num mero depósito de seres humanos, os quais, nesta sociedade, [...] são convertidos em inimigos públicos número um, tornam-se bodes expiatórios responsáveis por todos os nossos males" (KILDUFF, 2010).

Cordeiro (2015) observa que cada época histórica pertence a uma linha de pensamento e uma produção decorrente desses pensamentos, que reflete a cultura (como ideias de pensamento) nesse espaço-tempo de referência. Também observa que a materialização dessas ideias apresenta diferentes metodologias projetuais e construtivas que se relacionam com valores culturais de cada época. Sendo assim, os espaços construídos podem ser considerados como expressão dos conceitos de cada momento histórico. Com a arquitetura de estabelecimentos penais não é diferente.

A prisão não adveio de um projeto, mas do surgimento da necessidade de espaço para o cumprimento da pena, aperfeiçoandose através do planejamento com ideias e regras discutidas [...], mas sem reflexões conceituais que embasassem tais ideias, transformando-se de maneira cíclica, sem grandes avanços quanto à organização espacial (CORDEIRO, 2010, p.35).

O estudo apresentado é resultado da disciplina eletiva Projetos Especiais (60 horas) da Faculdade de Arquitetura e Urbanismo da UFAL, cuja ementa aborda:

Projetos especiais. Tecnologias de controle do ambiente (ativo e passivo). A interação do projeto e o controle ambiental. Iluminação, proteção solar, aspectos relativos à acústica. Curva de visibilidade. Aspectos estruturais e instalações. Especificação e detalhamento de interiores. Elaboração de planta compatibilizada. Visita a obras. Análise do espaço edificado (Projeto Pedagógico do Curso - PPC, Faculdade de Arquitetura e Urbanismo, UFAL, 2006).

Participaram na disciplina oito estudantes interessados em projetos de arquitetura penal, dos quais quatro faziam parte da equipe PIBIC, um era agente penitenciário e os demais não tinham contato anterior com este tipo de projeto. Conteúdos teóricos e práticos resultantes da pesquisa contribuíram para a melhor compreensão das problemáticas projetuais da tipologia encontrada na atual Penitenciária Baldomero Cavalcante. Os projetos resultantes foram apresentados à Superintendência Geral de Administração Penitenciária (SGAP), pretendendo colaborar para o melhoramento do sistema prisional alagoano. Desenvolvendo uma atividade extensionista, a disciplina propunha projeto de reforma da Penitenciária Baldomero Cavalcante, estabelecimento de regime fechado de segurança máxima. A proposta se pautava numa releitura do espaço penal existente, a fim de adequá-lo para o regime semiaberto, conforme sugestões feitas pela própria equipe da SGAP.

O interesse em trabalhar com a reforma do Baldomero Cavalcante partiu da constatação de sua ineficiência funcional, visto que, esse espaço se encontrava em estágio transitório de regime fechado para semiaberto. Até aquele momento, lidávamos, no sistema penal de Alagoas, com a inexistência de unidades para cumprimento de pena no regime semiaberto que permitiriam aos detentos trabalhar durante o dia e passar a noite na prisão, pois a unidade de regime semiaberto havia sido interditada há cerca de sete anos, a pedido do Ministério Público, em função da falta de fiscalização e inadequação de unidades prisionais, descumprindo o que determina o sistema progressivo da pena pela Lei de Execução Penal (BRASIL, 1984). Vale ressaltar que, embora o Estado reconheça a necessidade de aperfeiçoamento da "tecnologia disciplinar" (FOULCALT, 1996) para os estabelecimentos penais, não parece haver disposição para o aprofundamento dos conhecimentos relacionados aos espaços prisionais. O controle de acesso para a compreensão do espaço prisional como dispositivo de tecnologia disciplinar se justifica pelo argumento da segurança e, interessantemente, é exatamente a falta de conhecimento da realidade prisional que dificulta a manutenção da segurança, que se pretende preservar com a restrição do conhecimento do tema. 
Neste ínterim, não podemos deixar de agradecer a enorme contribuição da SGAP, que não apenas nos cedeu os projetos arquitetônicos, mas também permitiu que visitas e entrevistas fossem feitas nos estabelecimentos penais com enorme disponibilidade e segurança.

\section{Metodologia da disciplina}

A disciplina Projetos Especiais foi subdividida em três partes, a saber:

- $\quad$ Parte 1 - Referencial teórico sobre estabelecimentos penais: Embasada em conceitos humanizadores da arquitetura que "buscam canalizar a necessidade humana por ambientes enriquecedores, vivos e saudáveis" (BARROS, PINA, 2012) assim como em princípios de sustentabilidade para humanizar a arquitetura, pôde-se entender que os espaços humanizadores se configuram como estratégias de inserção social e, consequentemente, potenciais cenários de diminuição da violência dentro dos espaços prisionais (CORDEIRO, 2009). Neste ínterim, Kowaltowski (1980, apud BARROS, PINA, 2012) "propõe princípios para humanizar a arquitetura em termos da constância de necessidades sensoriais, de privacidade, territorialidade, segurança, orientação espacial e estética". Alexander (2013) também foi adotado para delimitações de parâmetros de arquitetura que pudessem ser utilizados na arquitetura penal. Esta reflexão promoveu discussões teóricas sobre o espaço penitenciário, pautando-se na humanização dos espaços como conceito de "tecnologia social". Neste sentido, considerando humanização do espaço penal como potencialidade de segurança, uma vez que o caráter opressor do espaço não auxilia na reinserção social do indivíduo, sendo necessário encontrar soluções que amenizem o sentimento de aprisionamento fazendo-se cumprir, também, o papel punitivo deste ambiente.

- $\quad$ Parte 2 - Visita a campo e levantamento: Realizadas na $2^{\text {a }}$ semana de aula (6h), as visitas a estabelecimentos penais foram realizadas em consonância com as visitas programadas pela pesquisa PIBIC. Nelas o grupo de alunos da disciplina interagiu com o grupo de alunos da pesquisa, realizando entrevistas com os agentes penitenciários e observando o funcionamento das unidades do Estado de Alagoas. Em seguida, foi realizada visita ao estabelecimento Baldomero Cavalcante, para levantamento físico e conferencia com as informações de projeto.

- $\quad$ Parte 3 - Oficina de arquitetura: Com duração de 8 semanas, paralelamente com as leituras referentes à arquitetura penal, foram realizadas oficinas de projeto, em que os alunos desenvolveram o projeto em dupla, dialogando entre todas as equipes e buscando resolver as questões de projeto, tais como funcionalidade, fluxos, garantia de direitos dos atores que usam o espaço, espaços mais humanizados. Uma vez concluídos, os projetos desenvolvidos na disciplina foram doados para a SGAP, como sugestões de utilização e de adaptação do espaço do estabelecimento penal Baldomero Cavalcante, configurando-se numa atividade de extensão desenvolvida pelas atividades pesquisa e ensino.

O conteúdo deste artigo é de caráter descritivo/explicativo, apresentando a proposta arquitetônica elaborada como resultado das discussões na disciplina Projetos Especiais. O projeto de reforma exposto no artigo foi desenvolvido por uma das duplas de projeto da disciplina, sendo considerado o que melhor atendeu todas as problemáticas projetuais e conseguiu propor maior inovação em relação à configuração do espaço. Além da revisão bibliográfica e da análise de projetos arquitetônicos penais foram realizados estudo de repertório, com entrevistas semiestruturadas que investigaram a racionalização de fluxos e localização de ambientes e atividades, de maneira a viabilizar o uso dos componentes arquitetônicos como elementos preventivos de violência.

Após este embasamento teórico e a apreensão desta realidade, definiu-se o programa de necessidades, dimensionamento básico, estudo de fluxos e gestão para análise do funcionamento interno do estabelecimento, a definição dos novos usos e fluxos da penitenciária sujeita a reforma, assim como dos materiais mais recorrentes em estabelecimentos penais. A partir das informações e sua análise, a metodologia do design thinking foi utilizada para a definição do partido arquitetônico, representado pelas etapas de projeto, desde a elaboração do estudo preliminar até a etapa de anteprojeto de reforma, como citado por Silva et al. (2012) num "processo multifásico e não linear que permite interações e aprendizados constantes, onde o erro gera aprendizados que o ajudam a traçar direções alternativas e identificar oportunidades para a inovação". 


\section{ANÁLISE ESPACIAL}

A Penitenciária Baldomero Cavalcante atualmente se caracteriza pelo grande grau de violência. Ela é configurada por dois longos corredores que dão para salas de uso específico e os módulos de convivência no final do extenso corredor de mais de $1 \mathrm{~km}$ de comprimento. A entrada da unidade no corredor (Figura 1) é marcada pela hierarquia do espaço, pois o controle se encontra num nível um pouco mais superior do que o do corredor.

Figura 1 - Corredor de entrada da Penitenciária Baldomero Cavalcante
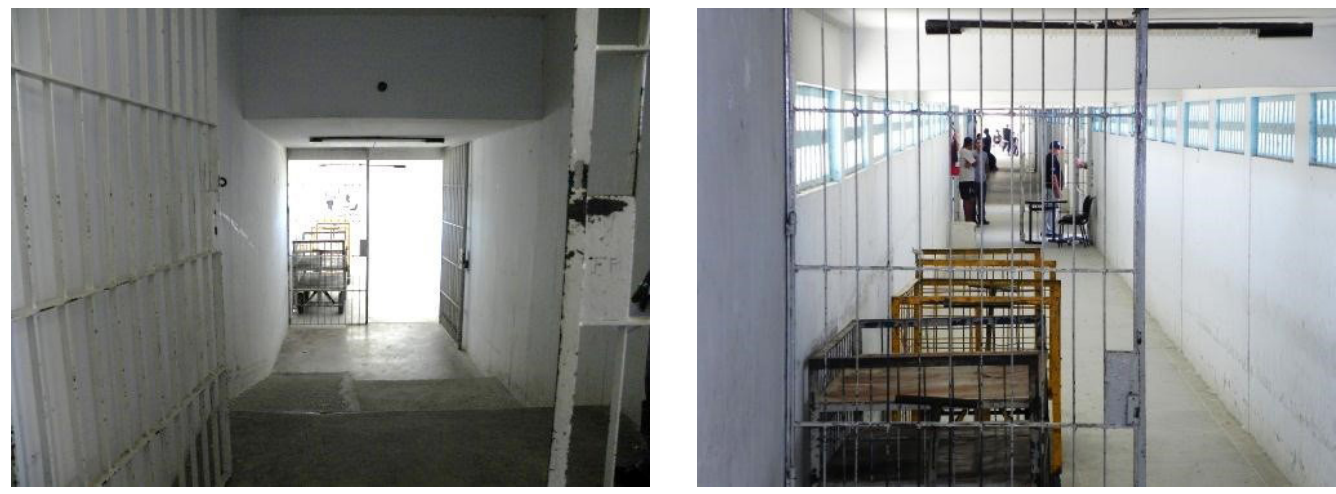

Fonte: PIBIC, 2013

Figura 2 - Planta geral da atual Penitenciária Baldomero Cavalcante

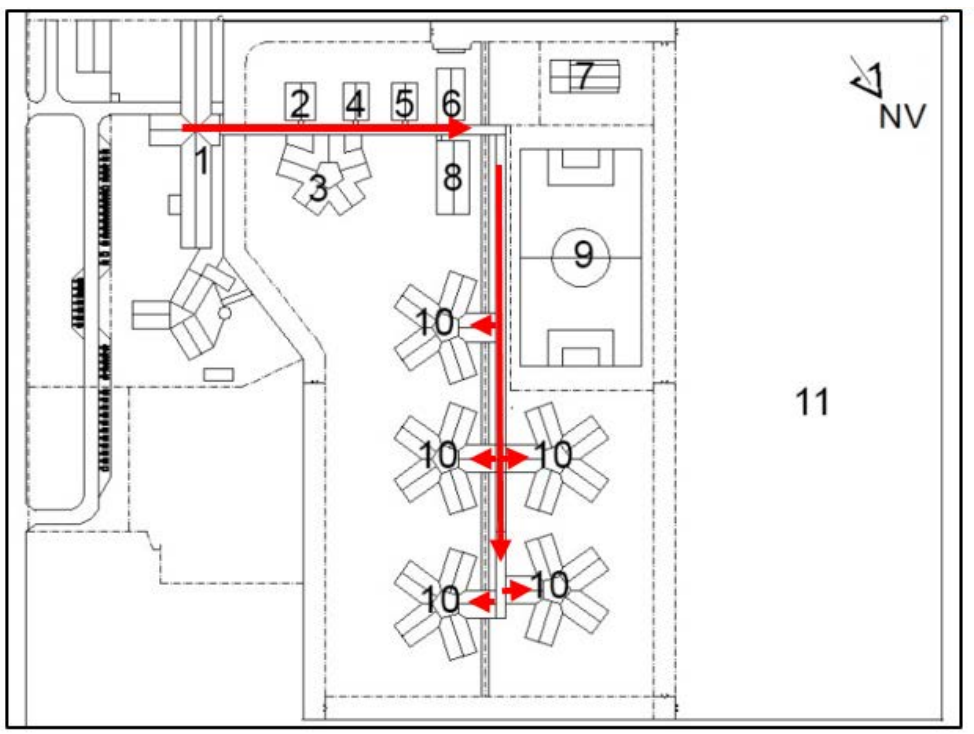

Legenda:

1 Administração/Recepção

2 Módulo de saúde

$3 \mathrm{COC}$

4 Triagem

5 Igreja

6 Cozinha

7 Canil

8 Módulo de ensino

9 Campo

10 Módulos de convivência/Celas

Observando a planta geral da penitenciária atual (Figura 2) destaca-se a localização da administração em relação aos módulos de convívio, onde a ligação entre elas se dá por um extenso corredor em forma de "L", o que possibilita, em eventos de rebelião, que a administração seja a última a escutar ou visualizar o acontecimento, gerando vulnerabilidade ao sistema e dificultando seu tempo de resposta e a assistência nos próprios módulos de convívio (celas).

Além disso, o fluxo gerado pelo extenso corredor principal da penitenciária provoca um direcionamento axial (Figura 2), apontado nas entrevistas como espaço de conflitos entre presos e agentes, que além de facilitar em uma maior aglomeração de força - pelo número alto de presos - em eventos contextuais, se configura em maior ou menor ameaça a segurança dos agentes. O fato de ser todo fechado, com pouca iluminação e ventilação, insalubridade e restrição visual, também proporciona um maior sentimento de aprisionamento, totalmente contrário aos conceitos de humanização do espaço. 
Figura 3 - Vista aérea da Penitenciária Baldomero Cavalcante

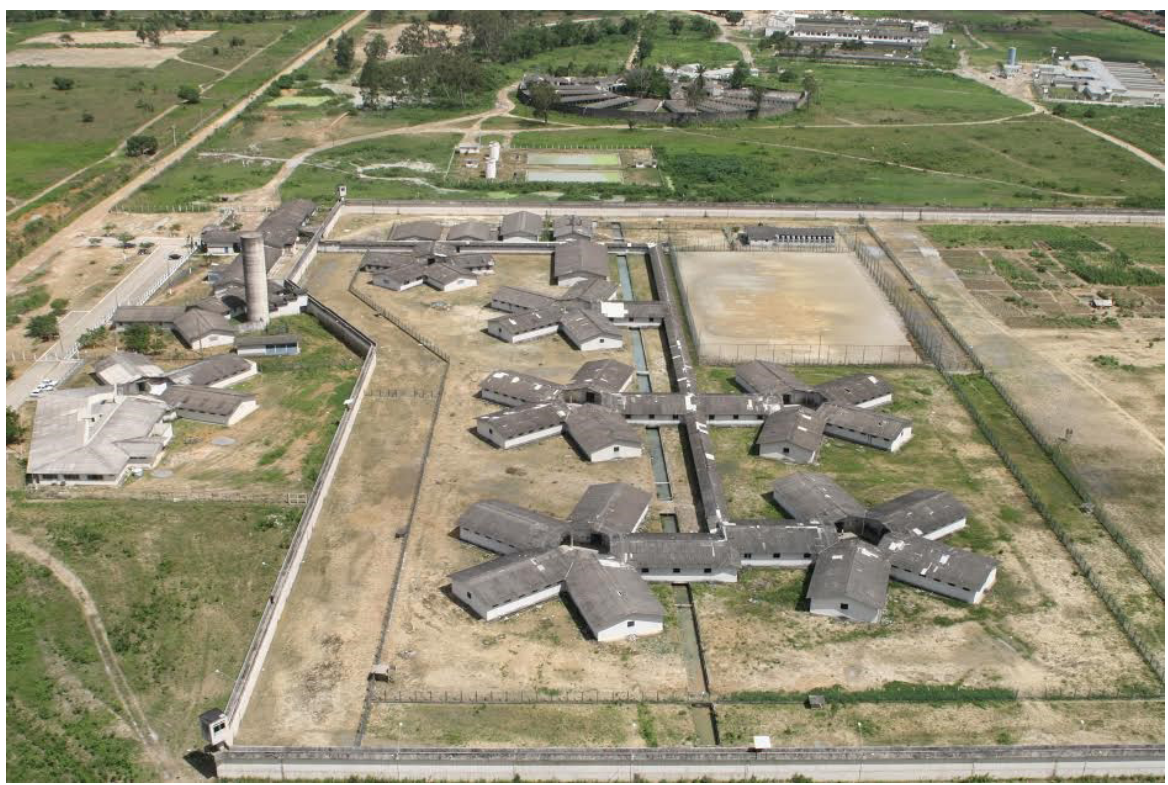

Fonte: SEVEAL, 2011

Os módulos de convivência da penitenciária analisada possuem uma configuração estrelar e paredes em bloco de concreto grateado, exceto nos dois últimos módulos do corredor central onde suas paredes são em concreto. Cada um dos cinco módulos é organizado internamente com um refeitório frontal (Figura 4) e logo após um pátio central aberto que dá para os chamados "raios" com corredores de celas dos dois lados (Figura 5). Nestes raios a visualização para as celas é praticamente nula, possuindo grandes áreas de sombra.

Sendo os módulos de convivência de configuração estrelar, o que torna a solução para estes espaços mais complexa no Projeto de Reforma da Penitenciária Baldomero Cavalcante, fora a concepção da penitenciária como um todo, este projeto deteve-se às configurações e especificações destes módulos em particular, para uma maior compreensão das problemáticas envolvidas neste espaço.

Figura 4 - Refeitório do Módulo de Convívio

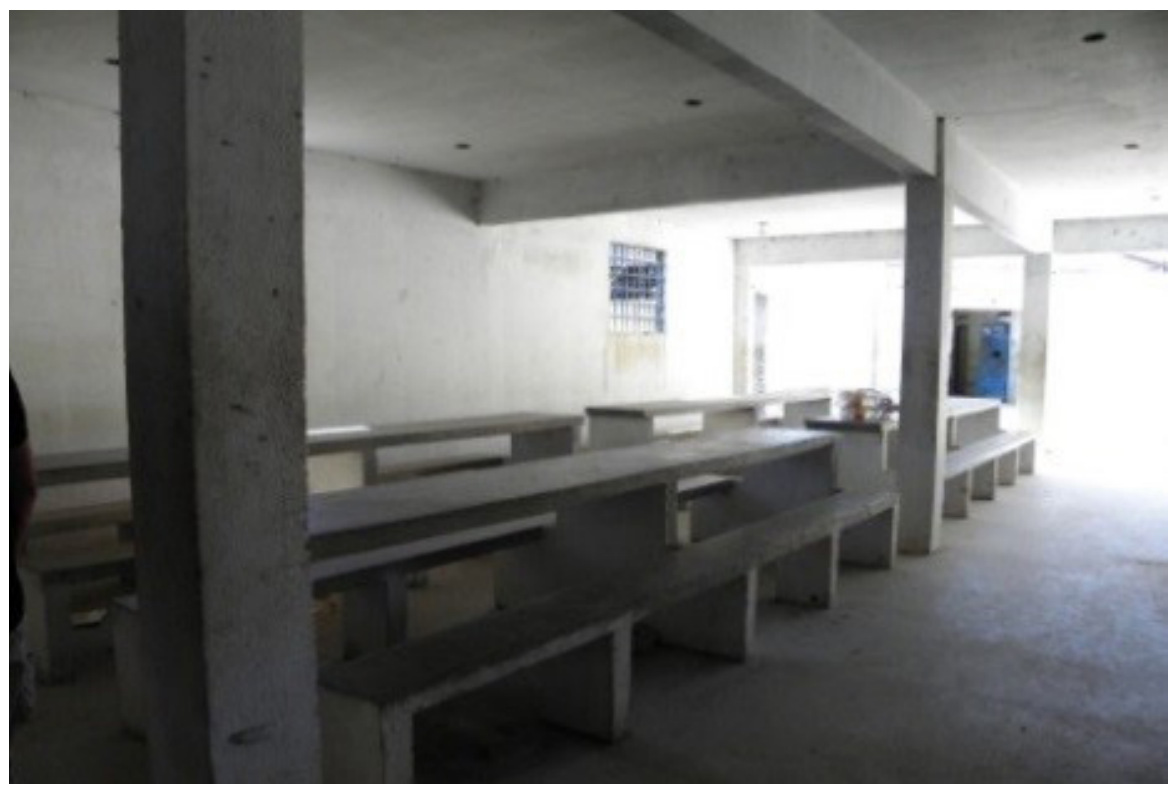

Fonte: PIBIC, 2013 
Figura 5 - Vista do pátio central do módulo de vivência e vista externa e interna de um dos raios de celas
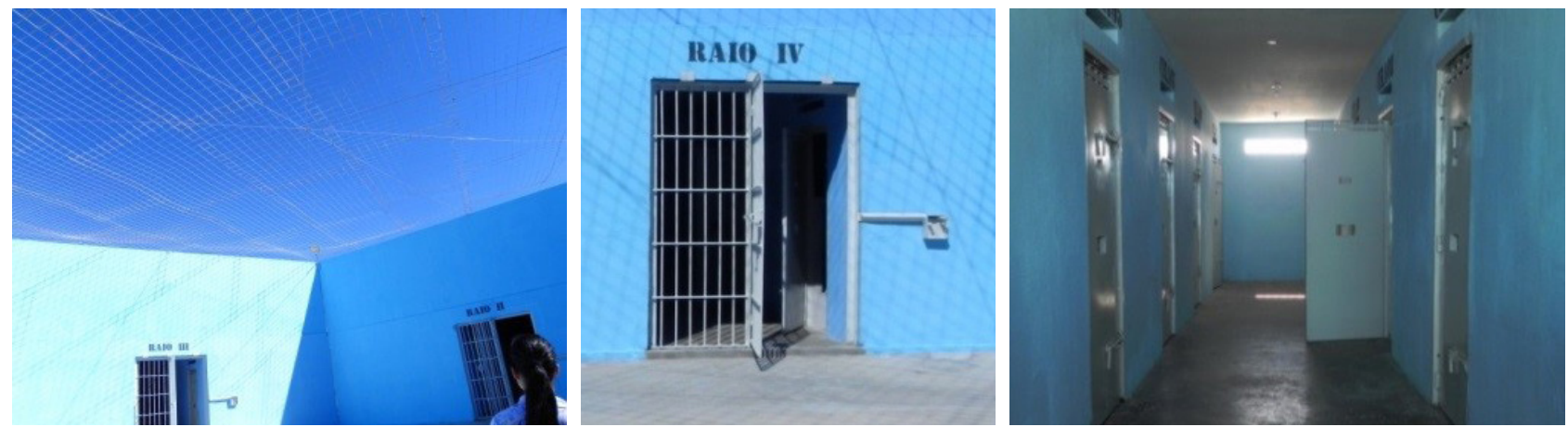

Fonte: PIBIC, 2013

Figura 6 - Vista dentro e fora da cela pela viseira da porta
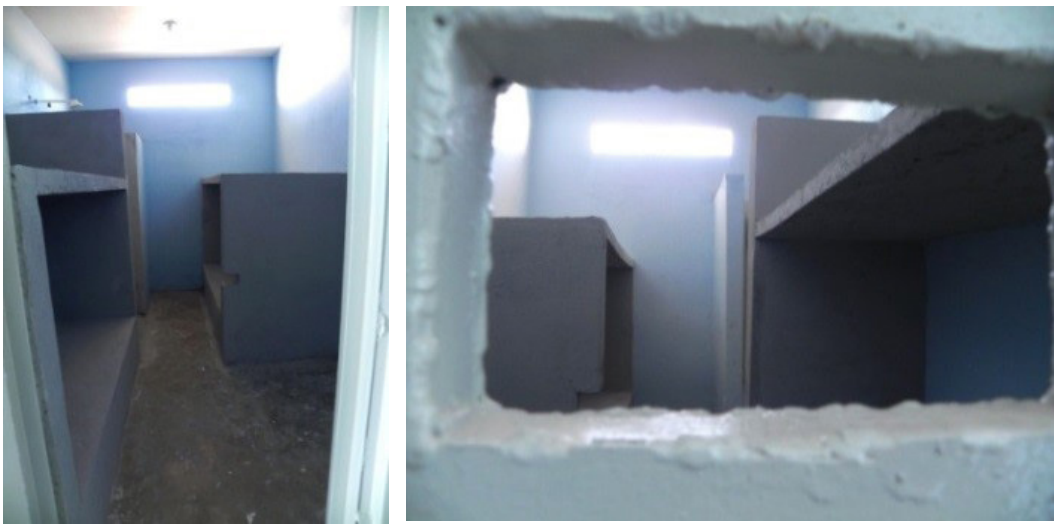

Fonte: PIBIC, 2013

Figura 7 - Planta baixa do Módulo de Convívio / Visualização e Rota/ Módulo de Convívio - áreas de sombra
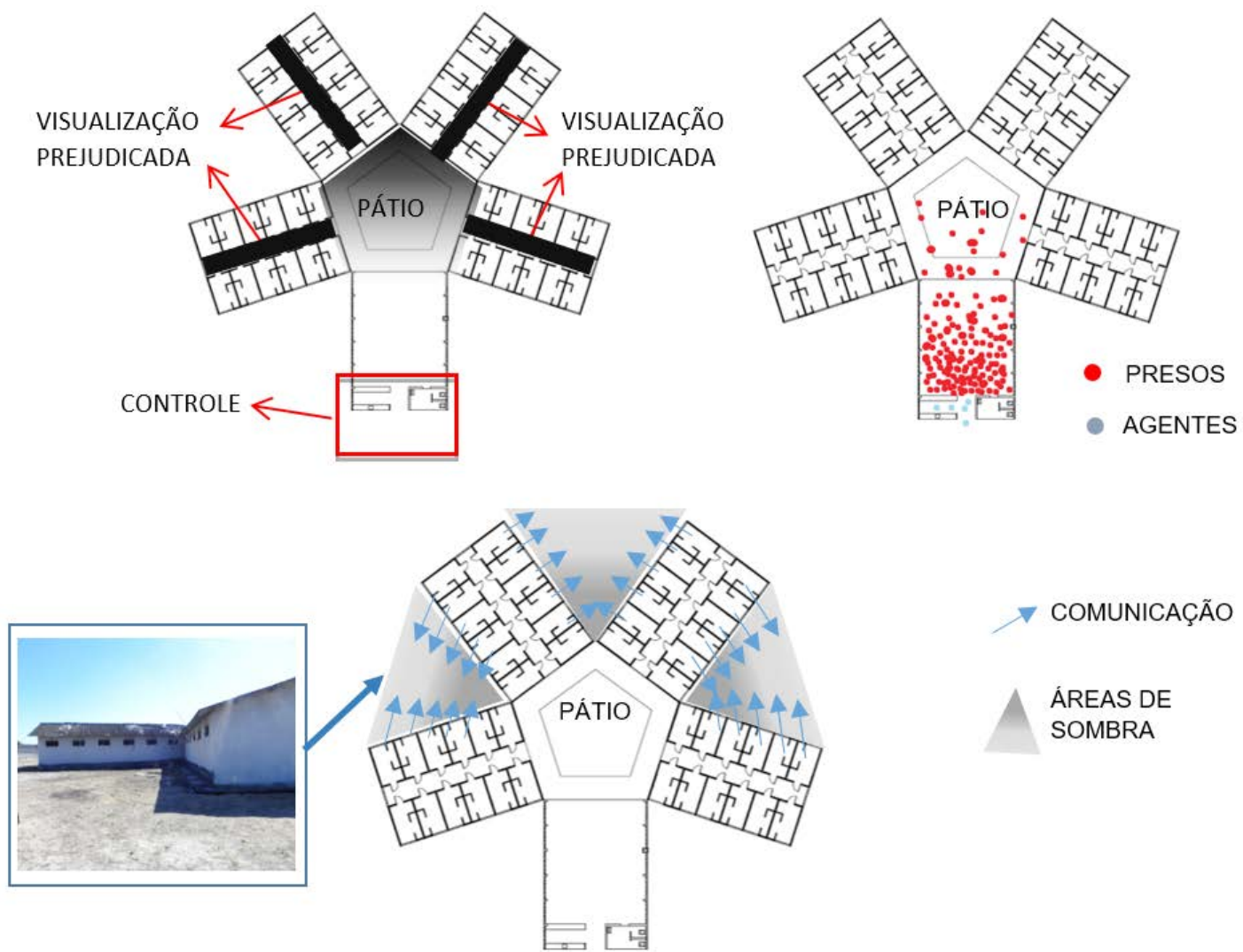
Na análise feita nos módulos constata-se que cada um dos cinco módulos é composto por quatro raios vinculados por uma área descoberta onde está localizado o pátio. O modelo permite ao controle toda visualização do pátio, por outro lado dificulta a visualização dos presos (Figura 5) deixando os mesmos mais vulneráveis a conflitos entre si, levando em consideração que a entrada do agente é dificultada, pela própria configuração do espaço, se limitando a entrar até a gaiola de controle de acesso de cada módulo. Além da falta de visualização do agente sobre o preso, também não há visualização de uma cela para a outra visto o componente da porta ser todo chapado e com apenas uma viseira pequena.

Ao mesmo tempo em que isto diminui a visualização entre os próprios presos e prejudica a ventilação natural da cela (Figura 6), também proporciona maior privacidade para quem está dentro de cada cela. Esta privacidade pode ser positiva, uma vez que o ser humano possui necessidade de privacidade em determinado espaço e tempo, ou negativa, no momento em que violências entre os próprios presos podem acontecer sem que ninguém veja.

O posicionamento dos raios, onde se encontram as celas, gera, também, a existência de áreas de sombra no intervalo entre os raios o que permite a comunicação entre os presos de um raio para o outro, pelas janelas das celas, facilitando ações ilícitas. Além disso, a rota torna-se estreita para a saída de tantos presos em caso de rebelião, permitindo uma maior aglomeração dos mesmos e facilitando o arrombamento e a destruição de componentes arquitetônicos, já que os detentos de todos os módulos podem se concentrar em um único pátio central (Figura 7).

\section{SOLUÇÕES ESPACIAIS}

O Primeiro passo para elaboração do Anteprojeto de Reforma da Penitenciária Baldomero Cavalcante de Regime Fechado para Regime Semiaberto, após o estudo feito em relação aos conceitos de humanização e segurança do espaço foi a definição dos novos usos e fluxos da penitenciária.

A partir da análise feita a priori, o projeto de reforma da penitenciária em estudo (Figura 8) visa não somente a inserção da população carcerária que sai do Regime Fechado numa nova expectativa de liberdade, mas a reinserção daqueles que, teoricamente, se encontram hoje em Regime Semiaberto, porém cumprindo sua pena fora do estabelecimento e sem vigilância. Para tanto, o projeto de reforma teve como ponto de partida um rearranjo espacial (ver Figura 8) que permitisse maior fluidez e dinamismo (Figura 9 e Figura 10) quebrando assim a fragilidade e a monotonia dos extensos corredores fechados.

Figura 8 - Planta geral do Projeto de Reforma da Penitenciária Baldomero Cavalcante

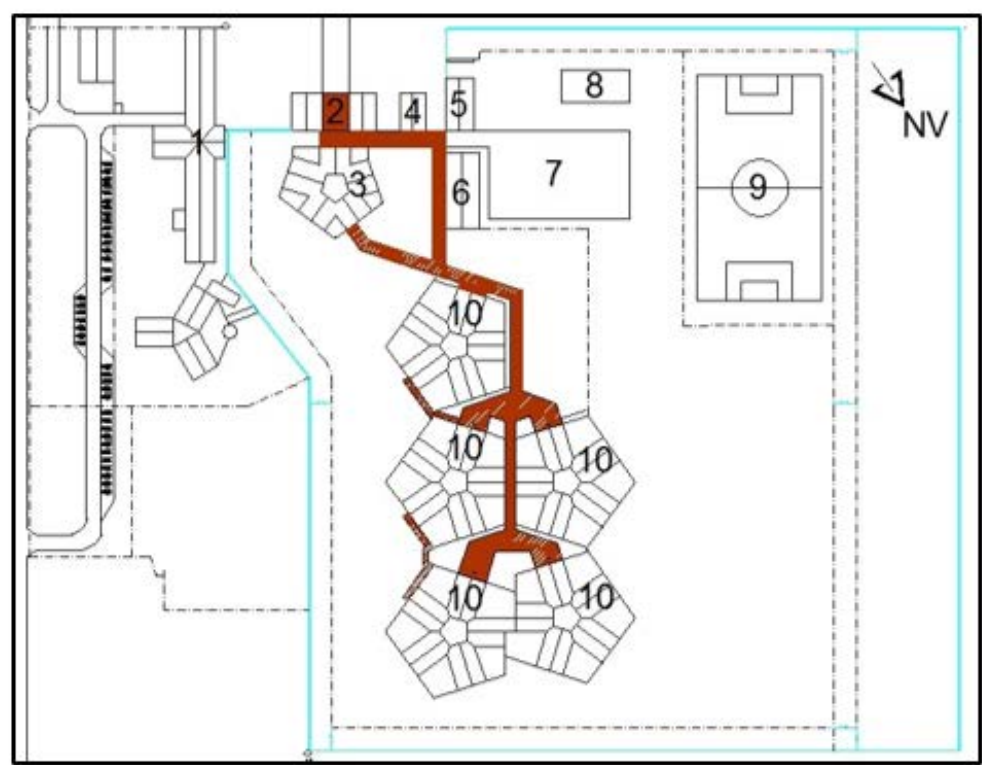

Legenda:

1 Escola e Centro de capacitação

2 Administração / Recepção

3 Módulo de visitas

4 Cozinha

5 Apoio $p$ / atividades culturais e religiosas

6 Módulo de saúde

7 Área de convívio

8 Canil

9 Campo

10 Módulo de convivência/Celas 
Figura 9 - Perspectiva geral do Anteprojeto de Reforma

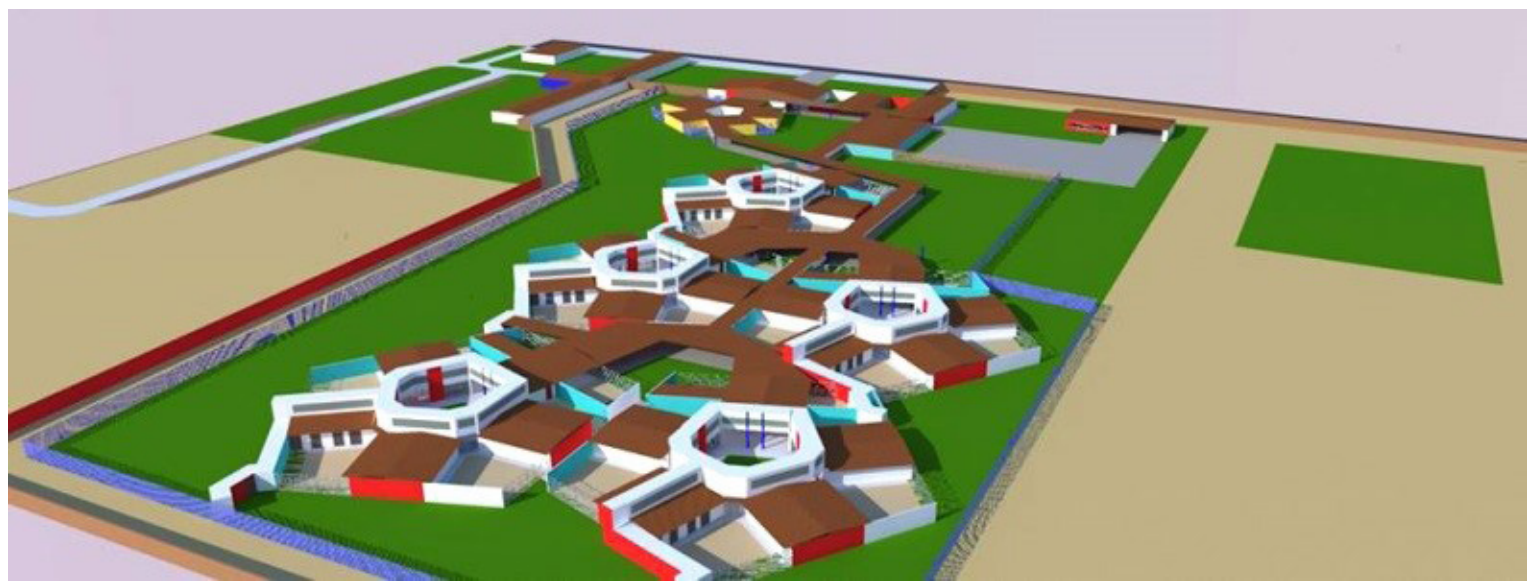

Fonte: Lima, 2013

\section{Usos e localidades}

Em relação aos novos usos e localidades pode-se observar que todos os blocos pré-existentes mantiveramse, porém com novos usos, conexões, layouts e com a adição de novos espaços. Observa-se, também, que, mesmo não interferindo em sua modulação, é evidenciada neste projeto de reforma a tentativa de adequação da penitenciária em estudo ao modelo campus (Figura 9), com reprodução de sua permeabilidade, jogo de volumes e vazios constituídos por blocos soltos no lote, conectados apenas pelo agenciamento coberto e contornados por alambrados a determinadas distâncias, o que permitiu a sensação de amplitude e visibilidade pelo passeio e dentro dos próprios módulos.

Figura 10 - Perspectiva dos novos corredores e agenciamento

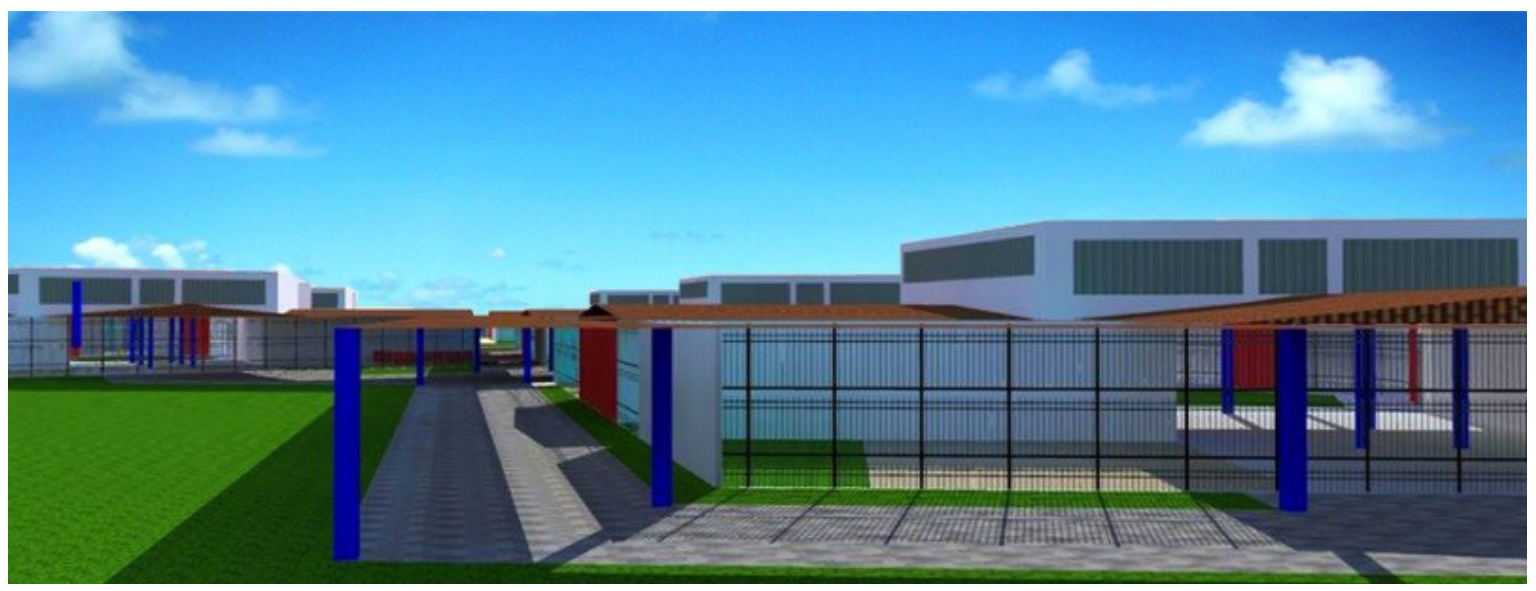

Fonte: Lima, 2013

Figura 11 - Perspectiva externa e interna dos novos módulos de convivência

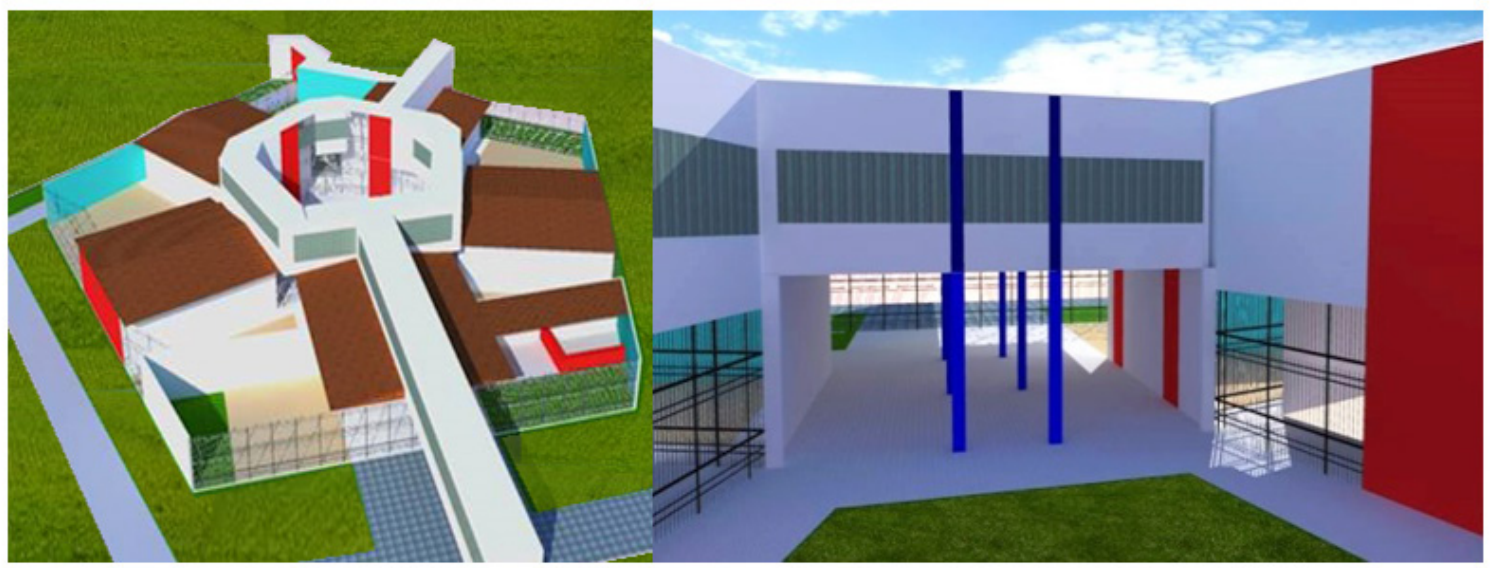

Fonte: Lima, 2013 
Primeiramente, a administração, recepção e almoxarifado foram relocados para onde funcionavam os blocos de saúde e triagem, necessitando da criação de um novo layout e da ampliação destes espaços (Figura 12). Esta nova localização facilita um maior controle de entrada e saída do visitante. Numa espacialização horizontal, em que todos os blocos de serviços encontram-se próximos, sendo a recepção em frente ao módulo de visitas, o visitante não terá contato com nenhum outro setor, assim como, o detento teria acesso direto ao módulo de visita. A antiga Administração por sua vez recebeu a nova função de Escola e Centro de capacitação, agora com acesso externo para que o detento saia do ambiente da penitenciária no momento em que vai estudar, reproduzindo o que ele faria fora do sistema.

Figura 12 - Recorte espacial 1 (Escola, Adm/Recepção/Almoxarifado, Módulo de visitas, Cozinha, Apoio para atividade religiosas e culturais e Módulo de saúde

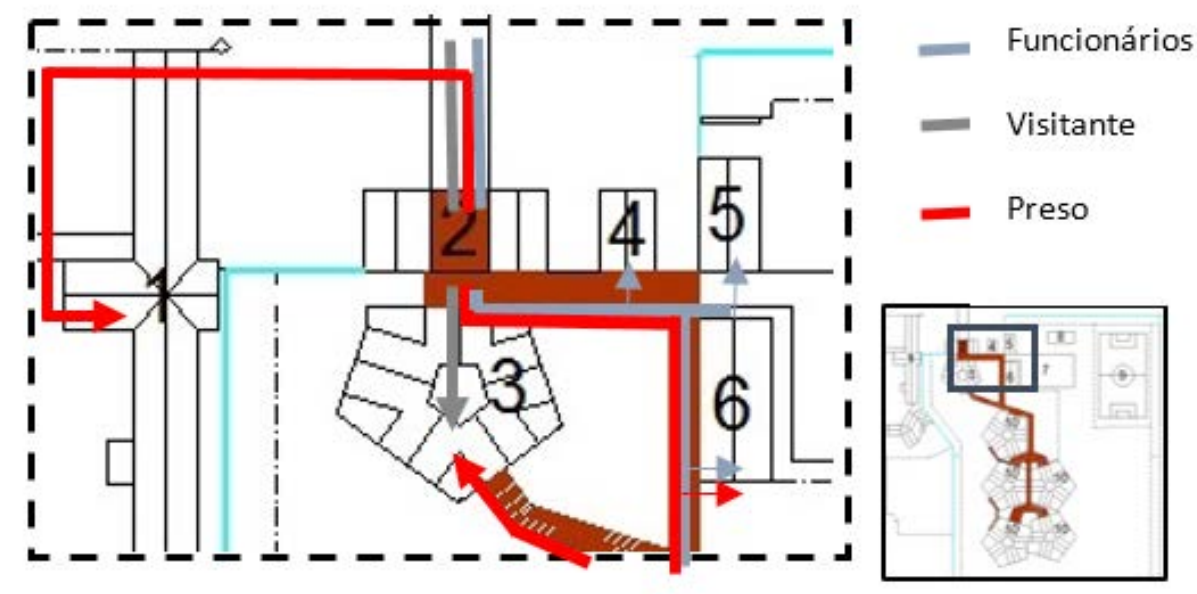

Fonte: Lima, 2013

Em relação aos módulos de convivência (Figura 13) estes continuaram com o mesmo uso, aproveitando sua modulação, porém foram alteradas suas conexões retirando o antigo corredor fechado na adaptação ao modelo Campus e adicionando um pavimento superior para vigilância das celas (controle) e dos novos pátios criados.

Figura 13 - Recorte espacial 2 (Módulos de Convivência - Celas)

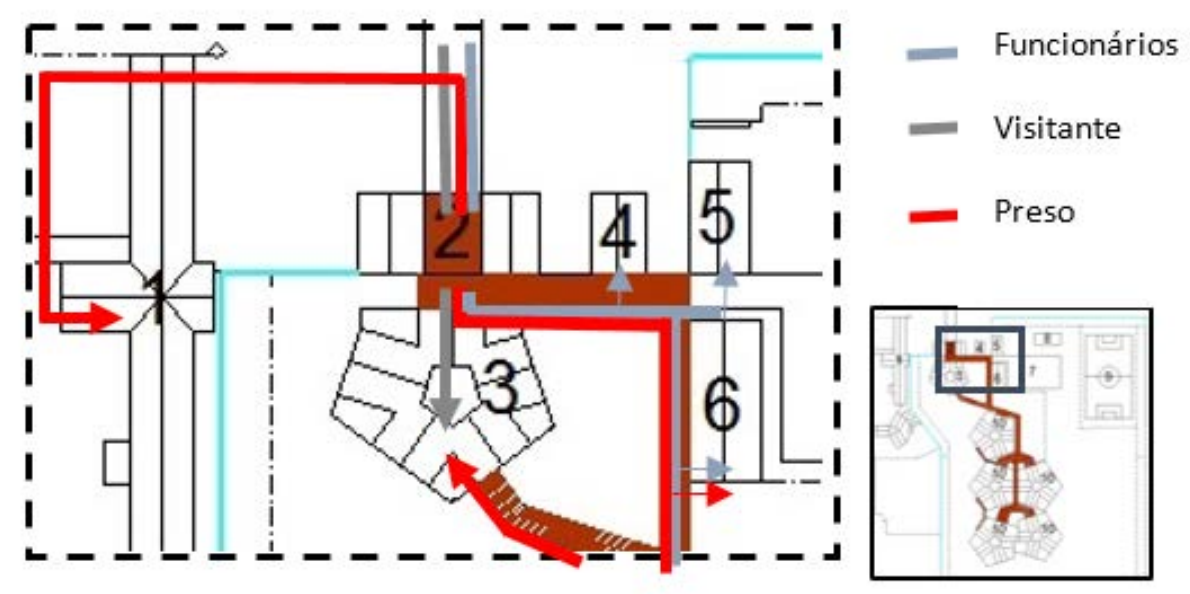

Fonte: Lima, 2013

\section{Layout e Especificações}

Na tentativa de solucionar os conflitos nos módulos de convivência foi proposto uma readaptação espacial que fragmentasse esses módulos em sub-módulos (Figura 14), diminuindo a concentração de presos em um só pátio central e dando a eles um novo espaço onde possam desenvolver atividades como hortas ou artesanato, para diminuição de sua ociosidade dentro do sistema e sustentabilidade do mesmo. 


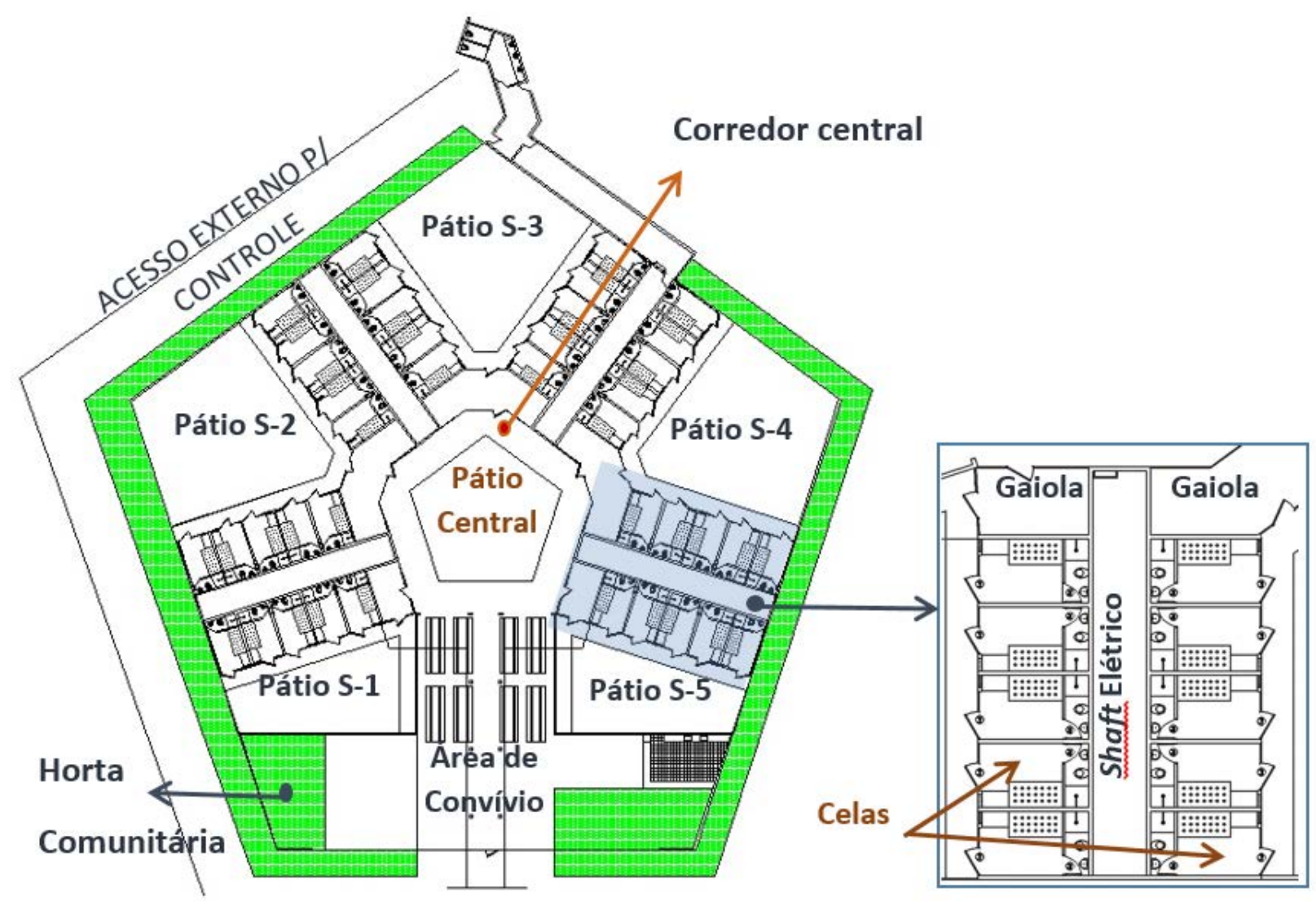

Fonte: Lima, 2013

Encontram-se agora em cada módulo cinco submodelos, cada um com uma gaiola em seu acesso para maior segurança do agente, com isso os antigos corredores das celas foram transformados em shafts elétricos. A criação desses shafts é de grande importância para que, durante possíveis manutenções e reparos na instalação elétrica, as celas não precisem ser esvaziadas visto que o serviço será realizado numa área externa ao módulo. Para facilitar este processo todas as lâmpadas das celas deverão ser instaladas embutidas nas paredes que dão para o shaft elétrico de cada submodelo, sendo protegidas por uma grade no interior da cela e podendo ser removidas e trocadas de dentro dos shafts.

Com isso, as portas que antes eram voltadas para os atuais shafts, foram relocadas para fora do raio onde foi criado um novo pátio que se repete em todos os intervalos de um raio e outro - que antes se configuravam como áreas de sombra - pretendendo garantir mais áreas livres para o preso, facilmente visualizadas pelo controle (Figura 15).

Figura 15 - Visualização do Controle para os pátios

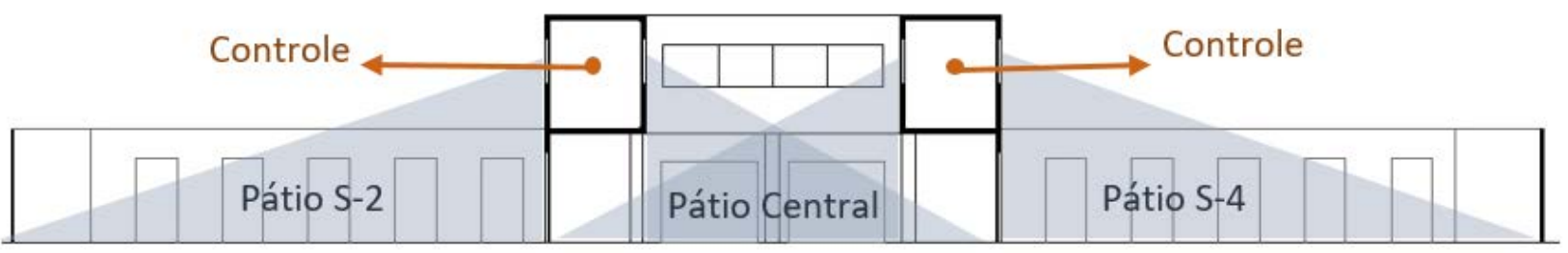

Fonte: Lima, 2013

O controle (Figura 15 e 16), por sua vez, foi proposto como um pavimento superior que não só consegue visualizar os novos pátios, mas também parte das celas. As portas das celas, antes em chapa de ferro galvanizado, com 112" de espessura, possuindo apenas uma viseira, foram substituídas por portas 
pneumáticas vazadas com grades de aço, que além de permitir a visualização do preso pelos outros presos e pelos agentes - constrangendo possíveis atitudes ilícitas ou de violência - possibilita a ventilação e iluminação natural, aeração e, consequentemente, melhores condições de salubridade ao ambiente. Todas as portas devem ser instaladas abrindo para a mesma direção - caso um preso não esteja com sua porta trancada na hora do fechamento das celas (hora da tranca) isto é mais facilmente visualizado pelo controle.

Figura 16 - Planta baixa - Controle Tipo (Plataforma Superior)

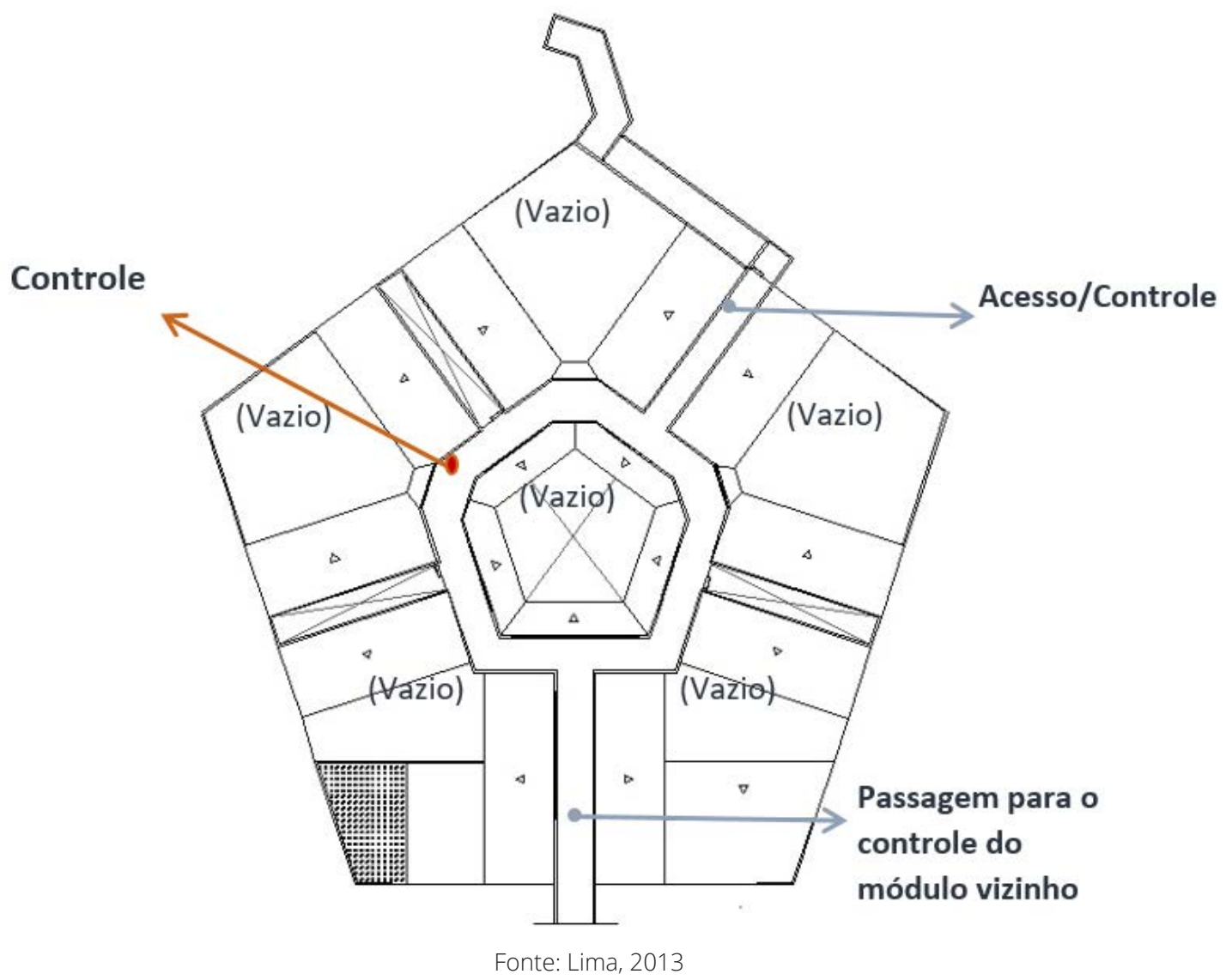

O piso foi mantido em granilite, as paredes externas e teto pintados com tinta Latex PVA enquanto que as paredes internas, divisórias entre celas, tiveram o revestimento em manta vinílica. Um fator importante é que dificilmente este material possibilita o uso como elemento cortante. O Glass Reinforced Concrete (GRC) foi utilizado para mobiliário, tanto nas bancadas de cada cela como nos vasos sanitários, encapsulados com GRC, considerados mais seguros que os vasos em cerâmica (que podem se transformar em armas) ou em inox que são facilmente retirados pelos presos que usam sua tubulação para esconderijo de armas.

Em relação às especificações do controle, localizado numa plataforma superior ao corredor central, com entrada restrita e acesso externo pelo agente, foi especificado janelas blindadas em vidro fumê, fazendo com que o preso não tenha controle do momento em que está sendo observado pelo agente e se sinta constrangido a cometer qualquer infração e, ainda, para que o preso não possa escutar os passos dos agentes no andar superior, o piso do controle especificado foi o acústico flutuante PA - 15dB VIBRASOM sobre a laje de alvenaria. Também foram colocadas câmeras filmadoras nos shafts elétricos e no corredor de acesso ao controle, evitando que o agente utilize esses espaços para usar de violência com o preso.

\section{CONSIDERAÇÕES FINAIS}

A experiência da disciplina Projetos Especiais demonstrou que a relação triádica pesquisa, ensino e extensão pode e deve ser incentivada na formação dos arquitetos, uma vez que esta relação possibilita um enorme amadurecimento no que tange à resolução de problemas de projeto arquitetônico. A compreensão teórica avançada demonstra a riqueza de repertório e reflexão sobre soluções viáveis para projetos de arquitetura de espaços complexos. 
A discussão da proposta de Reforma da Penitenciária Baldomero Cavalcante serviu, principalmente, para a reflexão acerca de um programa complexo como a arquitetura penal, que até hoje se encontra pouco estudada e questionada. O fazer arquitetura, vai além da matéria física, pois são inerentes a este espaço sujeitos muitas vezes desprovidos de direitos e estigmatizados pela sociedade, que se apresenta preconceituosa e atenta, exclusivamente, à exclusão destes sujeitos como solução para a segurança neste tipo de projeto. Desta forma, podemos encontrar, na maioria das penitenciárias existentes, espaços fechados, insalubres, sem ventilação ou iluminação, que negam qualquer intenção de ressocialização através da arquitetura, e podem ser considerados "desumanos". Somente num processo inverso do pensamento no ato de projetar, fruto de uma análise do que já existia e da realidade prisional, pôde-se identificar as problemáticas deste espaço que ajudam a traçar direções alternativas e resultam na inovação desta tecnologia na busca de soluções, considerando o real funcionamento deste estabelecimento e até onde a arquitetura pode ajudar na humanização, seja através da escala, da amplitude, do conforto, da visualização como segurança ou das sensações provocadas pelo espaço, como foi explorado no Projeto de Reforma da Penitenciária estudada.

\section{REFERÊNCIAS}

ALEXANDER, C.; ISHIKAWA, S. ; SILVERSTEIN, M.; JACOBSON, M.; KING, I. F.; ANGEL, S. Uma linguagem de padrões (a pattern language). Porto Alegre: Bookman Editora, 2013.

BARROS, R. R. M. ; PINA. S. M. A humanização no projeto de habitação coletiva. In: KOWALTOWSKI, D. C. C. K. ; MOREIRA, D. C.; PETRECHE, J. R. D.; FABRICIO, M. M. (Orgs.). O Processo de Projeto em Arquitetura da Teoria à Tecnologia. São Paulo: Oficina de textos, 2012 , p. $245-272$.

BRASIL. Presidencia da Republica. Casa Civil (Comp.). Lei no 7.209 - Código Penal. 1984. Disponível em: <http://www.planalto.gov.br/ ccivil_03/LEIS/1980-1988/L7209.htm\#art1>. Acesso em 19 Maio 2014.

BRASIL. Conselho Nacional de Politica Criminal e Penitenciaria. Resolução CNPCP nº 09/2011, de 18 de novembro de 2011. Dispõe sobre as Diretrizes básicas para arquitetura prisional. Publicada no DOU. 111p.

CORDEIRO, S. F. De perto e de dentro: a relação entre o indivíduo encarcerado e o espaço arquitetônico penitenciário a partir de lentes de aproximação. 1. ed. Maceio: EDUFAL, 2009. 267p

CORDEIRO, S. F. Até quando faremos relicários? a função social do espaço penitenciário. 2. ed. rev. e amp. Maceió: EDUFAL, 2010.

CORDEIRO, S. F.; LIMA, C. C.; CARVALHO NETO, A. B.; CORREIA, D. A.; MADEIRO, J. Manual sobre Arquitetura Penal: segurança x humanização. 1. ed. Maceio: EDUFAL, 2015. 222p.

FOUCAULT, M. A ordem do discurso. Tradução de Laura Fraga de Almeida Sampaio. São Paulo: Loyola, 1996.

FOUCAULT, M. Nietzsche, a genealogia e a história. In: MACHADO, R. (Org.). Microfísica do poder. São Paulo: Editora Graal, 2004.

KILDUFF, F. O controle da pobreza operado através do sistema penal. Rev. katálysis vol.13 n.2 Florianópolis, 2010.

LIMA, G. F. C. O debate da sustentabilidade na sociedade insustentável. Revista Política \& Trabalho, nº 13: 201-222, João Pessoa: PPGS/ UFPB, setembro/1997.

SILVA, M. J. V.; VIANNA, Y.; ADLER, I.; LUCENA, B.; RUSSO, B. Design Thinking: Inovação em Negócios. Rio de Janeiro: MJV Press, 2012. 162p.

NOTA DO EDITOR (*) O conteúdo do artigo e as imagens nele publicadas são de responsabilidade do(s) autor(es). 